\title{
MR-guided spine interventions: time to get off the ground?
}

\author{
Alessandra Splendiani, Federico Bruno \\ Department of Biotechnological and Applied Clinical Sciences, University of L'Aquila, L'Aquila, Italy \\ Correspondence to: Federico Bruno. Department of Biotechnological and Applied Clinical Sciences, University of L'Aquila, Via Vetoio 1, 67100, \\ L'Aquila, Italy. Email: federico.bruno.1988@gmail.com. \\ Comment on: Böning G, Hartwig T, Freyhardt P, et al. MR-guided lumbar facet radiofrequency denervation for treatment of patients with chronic low \\ back pain in an open 1.0 Tesla MRI system. Ann Transl Med 2021;9:1056.
}

Submitted Sep 28, 2021. Accepted for publication Oct 11, 2021.

doi: $10.21037 / \mathrm{atm}-21-5167$

View this article at: https://dx.doi.org/10.21037/atm-21-5167

In their recently published article, "MR-guided lumbar facet radiofrequency denervation for treatment of patients with chronic low back pain in an open 1.0 Tesla MRI system", Böning and his research team evaluate the feasibility, safety, and efficacy of lumbar facet joint radiofrequency denervation (FRD) under MRI guidance, using an open 1.0 Tesla scanner (1).

The study results confirm the clinical efficacy of the FRD procedure in terms of pain reduction at the mediumterm follow-up, as demonstrated in the previous literature (2-4). The use of the MR guide represents the peculiarity of this report, and opens up space for a series of important reflections.

Spinal interventional radiology, thanks to the high procedural success, together with its minimal invasiveness and a high safety profile, has been gaining an increasingly wider field of applications, either for degenerative, neoplastic, and inflammatory pathology, with several techniques, procedures, implantable materials, and injectable drugs available (4-10).

The need for real-time imaging guidance makes fluoroscopy a fundamental guiding method, and CT is another modality of choice, thanks to the high-spatial resolution sectional visualization (11).

MR guidance provides a sectional visualization, with the advantage of having a significant profit in tissue contrast resolution. The latter is a major advantage, especially in cases where bone or soft tissue lesions poorly delineated by non-contrast CT scan have to be targeted, or in body districts where the anatomical characterization of nervous and vascular structures is a priority, even without contrast medium administration (12).

An excellent compromise between the contrast resolution provided by MR imaging and the speed of a real-time guide can be given by ultrasound-MRI fusion navigation systems, quite used and widespread for biopsy guidance and lumbar fact joint injections. This US-MRI fusion approach performed at the CT gantry, and combined with this guide, could be an appealing solution for many procedures $(13,14)$.

Indeed, the MRI guidance for interventional radiology procedures, especially around the spine, is not an absolute novelty. In literature, there are reports on the use of the MRI guidance to carry out procedures such as nerve root injection, facet joint injection, epidural injection, facet joint neurotomy, and biopsies, dating back even to the last decade $(15,16)$.

Nevertheless, it seems that there has not been a rampant increase in the application of this procedure in recent years. There may be several critical factors to be assessed about this point. Definitely, the ergonomics of the MR environment, considering first and foremost the operating field space; from this point of view, open, low-field magnets provide greater handling and comfort. The disadvantage of these scanners $(0.2 \mathrm{~T})$ was mainly related to the low signalto-noise ratio, and the recent development of high-field scanners with wider gantry and high-field strength open magnets (1 T) may partially overcome these limitations (16). Furthermore, the sequences used are increasingly optimized to obtain quick imaging feedback with good needle/probe visualization.

Another critical aspect is represented by the availability and costs of MR-compatible materials, not only regarding needles and probes, but also the instrumentation for the 
anesthesiologic support inside the MRI room. Further studies are also needed to assess operator and patient comfort and safety, as well as procedural times, compared to fluoroscopic and CT guided procedures.

The absence of ionizing radiations using MR guidance is an undoubted advantage. Although this is a priority and tangible benefit for fertile women, children, and young subjects submitted to multiple procedures, there is a need to evaluate the cost-benefit ratio in elderly patients.

All these factors probably led to an unavoidable delay in the foundation of universal expertise, and therefore the rapid diffusion and availability of these procedures, advantageous from many points of view and with enormous clinical potential.

\section{Acknowledgments}

Funding: None.

\section{Footnote}

Provenance and Peer Review: This article was commissioned by the editorial office, Annals of Translational Medicine. The article did not undergo external peer review.

Conflicts of Interest: Both authors have completed the ICMJE uniform disclosure form (available at https://dx.doi. org/10.21037/atm-21-5167). The authors have no conflicts of interest to declare.

Ethical Statement: The authors are accountable for all aspects of the work in ensuring that questions related to the accuracy or integrity of any part of the work are appropriately investigated and resolved.

Open Access Statement: This is an Open Access article distributed in accordance with the Creative Commons Attribution-NonCommercial-NoDerivs 4.0 International License (CC BY-NC-ND 4.0), which permits the noncommercial replication and distribution of the article with the strict proviso that no changes or edits are made and the original work is properly cited (including links to both the formal publication through the relevant DOI and the license). See: https://creativecommons.org/licenses/by-nc-nd/4.0/.

\section{References}

1. Böning G, Hartwig T, Freyhardt P, et al. MR-guided lumbar facet radiofrequency denervation for treatment of patients with chronic low back pain in an open 1.0 Tesla MRI system. Ann Transl Med 2021;9:1056.

2. Cohen SP, Doshi TL, Constantinescu OC, et al. Effectiveness of Lumbar Facet Joint Blocks and Predictive Value before Radiofrequency Denervation: The Facet Treatment Study (FACTS), a Randomized, Controlled Clinical Trial. Anesthesiology 2018;129:517-35.

3. Juch JNS, Maas ET, Ostelo RWJG, et al. Effect of Radiofrequency Denervation on Pain Intensity Among Patients With Chronic Low Back Pain: The Mint Randomized Clinical Trials. JAMA 2017;318:68-81.

4. Tortora F, Negro A, Russo C, et al. Chronic intractable lumbosacral radicular pain, is there a remedy? Pulsed radiofrequency treatment and volumetric modifications of the lumbar dorsal root ganglia. Radiol Med 2021;126:124-32.

5. Marcia S, Zini C, Hirsch JA, et al. Steroids Spinal Injections. Semin Intervent Radiol 2018;35:290-8.

6. Zini C, Bellini M, Masala S, et al. Percutaneous Interspinous Spacer in Spinal-Canal-Stenosis Treatment: Pros and Cons. Medicina (Kaunas) 2019;55:381.

7. Marcia S, Zini C, Bellini M. Image-Guided Percutaneous Treatment of Lumbar Stenosis and Disc Degeneration. Neuroimaging Clin N Am 2019;29:563-80.

8. Arrigoni F, de Cataldo C, Bruno F, et al. Ablation, consolidation and radiotherapy for the management of metastatic lesions of the spine: impact on the quality of life in a mid-term clinical and diagnostic follow-up in a pilot study. Med Oncol 2020;37:53.

9. Palumbo P, Bruno F, Arrigoni F, et al. Diagnostic and interventional management of infective spine diseases. Acta Biomed 2020;91:125-35.

10. Bruno F, Carboni N, Palumbo P, et al. O2-O3 chemodiscolysis: How much, how long? Retrospective outcome evaluation of different treatment sessions in partially-responder patients. Interv Neuroradiol 2021. [Epub ahead of print].

11. Santiago FR, Kelekis A, Alvarez LG, et al. Interventional procedures of the spine. Semin Musculoskelet Radiol 2014;18:309-17.

12. Masciocchi C, Conchiglia A, Gregori LM, et al. Critical role of HIFU in musculoskeletal interventions. Radiol Med 2014;119:470-5.

13. De Silva T, Uneri A, Zhang X, et al. Real-time, imagebased slice-to-volume registration for ultrasound-guided spinal intervention. Phys Med Biol 2018;63:215016.

14. Xie P, Feng F, Cao J, et al. Real-time ultrasonography- 
magnetic resonance image fusion navigation for percutaneous transforaminal endoscopic discectomy. J Neurosurg Spine 2020. [Epub ahead of print].

15. Fritz J, Sequeiros RB, Carrino JA. Magnetic resonance imaging-guided spine injections. Top Magn Reson

Cite this article as: Splendiani A, Bruno F. MR-guided spine interventions: time to get off the ground? Ann Transl Med 2021;9(21):1609. doi: 10.21037/atm-21-5167
Imaging 2011;22:143-51.

16. Himes NC, Chansakul T, Lee TC. Magnetic Resonance Imaging-Guided Spine Interventions. Magn Reson Imaging Clin N Am 2015;23:523-32. 